\title{
Case Report: Nuchal Bursitis Associated With Borrelia burgdorferi Infection in a Horse
}

\author{
Cassandra Guarino ${ }^{1 *}$, Toby Pinn-Woodcock ${ }^{1}$, David G. Levine ${ }^{2}$, Julia Miller ${ }^{3}$ and \\ Amy L. Johnson ${ }^{2}$ \\ ${ }^{1}$ Population Medicine and Diagnostic Sciences, Cornell University, Ithaca, NY, United States, ${ }^{2}$ New Bolton Center, University \\ of Pennsylvania School of Veterinary Medicine, Kennett Square, PA, United States, ${ }^{3}$ General Medicine, Alliance Equine \\ Health Care, Glenmoore, PA, United States
}

\section{OPEN ACCESS}

Edited by:

Peter James O'Brien,

University College Dublin, Ireland

Reviewed by:

Francisco Ruben Carvallo Chaigneau, Virginia Maryland College of Veterinary

Medicine, United States

Marina Spinu,

University of Agricultural Sciences and Veterinary Medicine of Cluj-Napoca, Romania Valentina Virginia Ebani, University of Pisa, Italy

*Correspondence: Cassandra Guarino cg82@cornell.edu

Specialty section:

This article was submitted to Veterinary Experimental and

Diagnostic Pathology,

a section of the journal

Frontiers in Veterinary Science

Received: 17 July 2021

Accepted: 18 August 2021

Published: 23 September 2021

Citation:

Guarino C, Pinn-Woodcock T, Levine DG, Miller J and Johnson AL (2021) Case Report: Nuchal Bursitis Associated With Borrelia burgdorfer Infection in a Horse.

Front. Vet. Sci. 8:743067. doi: 10.3389/fvets.2021.743067
Cases of cranial nuchal bursitis associated with Borrelia burgdorferi infection have not been thoroughly described. Here, we describe the case of a 17-year-old mare that was presented for low head carriage, dull demeanor, and resistance to haltering. Imaging supported a diagnosis of nuchal bursitis, and bursoscopy with surgical debridement of the nuchal bursa was performed. B. burgdorferi was identified by molecular diagnostics in serial samples of the bursal fluid, with no other organisms identified. Serology revealed significant elevation in antibodies directed against OspA of B. burgdorferi, but not the typical infection markers, OspC and OspF. Intravenous ceftiofur was administered for 80 days, and the nuchal bursa was directly injected with ceftiofur. The mare recovered and was able to return to work with no recrudescence of clinical signs over the following year to date. Infection with $B$. burgdorferi should be considered as a differential in cases of septic nuchal bursitis.

Keywords: lyme disease, poll evil, ospA, lyme multiplex assay, equine, ospF, antibody

\section{INTRODUCTION}

Cranial nuchal bursitis, colloquially known as "poll evil", was originally thought to arise from trauma, but suspicion of a septic process was raised over a century ago (1). A variety of infectious causes have been implicated, including Brucella abortus (2), and both gram-negative and grampositive bacteria have been cultured from bursal fluid samples from affected animals (3). Nuchal bursitis typically presents with head and neck pain and abnormal head carriage, sometimes with swelling over the poll and an associated draining tract (4). A retrospective study of 30 horses treated after a diagnosis of cranial nuchal bursitis revealed that samples from two horses tested positive by PCR for B. burgdorferi, but the significance of these findings was unclear (3).

B. burgdorferi sensu lato infection and Lyme disease in horses is a controversial topic in equine clinical practice due to the paucity of available evidence for disease pathologies, combined with the high seroprevalence for B. burgdorferi in horses residing in Lyme endemic regions (5). B. burgdorferi infection occurs through the bite of an infected tick and can subsequently spread through the bloodstream to a variety of tissues within the mammalian host (6). In horses, B. burgdorferi infection is commonly diagnosed with the Lyme multiplex assay (7), where positive antibody response to the outer surface protein (Osp) OspF is evidence of historic or chronic infection with B. burgdorferi. OspA antibodies are typically considered evidence of vaccination (8), but low transient OspA antibody values can be detected early in the course of equine infection, as is also reported in dogs $(9,10)$. Some horses will produce a robust and persistent OspA immune 
response after infection with $B$. burgdorferi $(5,11)$, but little is known about the cause or significance of this variation in immune response to $B$. burgdorferi in the horse.

OspA antibodies have been detected late in the course of human $B$. burgdorferi infection, but only in a minority of cases $(12,13)$. Further, in humans, development of OspA antibodies after infection with $B$. burgdorferi has been associated with the clinical presentation of arthritis, where higher IgG responses to OspA correlate with more severe and prolonged arthritis (14). Here, we present a case of equine nuchal bursitis where $B$. burgdorferi was identified by PCR in serial bursal fluid samples, and only OspA antibodies were produced in response to this infection.

\section{CASE HISTORY}

A 17-year-old, 600-kg Warmblood mare was presented to her primary care veterinarian with low head carriage, dull demeanor, and resistance to haltering after having been on cetirizine hydrochloride (All Day Allergy, GoodSense, New Brunswick, NJ, $0.2-0.3 \mathrm{mg} / \mathrm{kg}$ PO q12h) due to multiple episodes of full body hives over the preceding 2 weeks. Prior to the development of clinical signs, the mare had been routinely maintained on a supplement for allergy (Platinum Skin and Allergy, Platinum Performance, Buellton, CA, $5.3 \mathrm{mg} / \mathrm{kg}$ PO q12h) to control Culicoides hypersensitivity that the mare commonly experienced during spring-fall, altrenogest (Regu-Mate; Merck Animal Health, Kenilworth, NJ, $0.044 \mathrm{mg} / \mathrm{kg}$ PO q24h) for behavioral modification, initiated approximately 5 years prior, and pergolide (Prascend; Boehringer Ingelheim, Duluth, GA, $0.0017 \mathrm{mg} / \mathrm{kg}$ PO q24h) for management of pituitary pars intermedia dysfunction (PPID) diagnosed the preceding year. Physical examination was unremarkable except for a raised line that appeared to be a superficial vessel running from the nuchal bursa area caudally down the right side of the neck toward the vertebral column; this finding had been evident for several days. Initial hematology revealed lymphopenia (989 cells/ $\mu$; reference interval (RI) 1,500-5,500 cells/ $\mu \mathrm{l}$ ). Lyme multiplex assay was negative for antibodies against OspC and OspF but was markedly positive for antibodies against OspA $(24,204$ median fluorescent intensity (MFI); RI <2,000 MFI). Serum amyloid A (SAA) (StableLab Equine Blood Analysis Kit, Sligo, Ireland) was elevated based on qualitative colorimetric read-out. Treatment was initiated with flunixin meglumine (Banamine; Merck Animal Health, Madison, NJ, $1.1 \mathrm{mg} / \mathrm{kg} \mathrm{IV}$, once) and minocycline (Aurobindo, East Windsor, NJ, $4 \mathrm{mg} / \mathrm{kg}$ PO q12h). Cetirizine treatment was discontinued.

Hives returned the following day and a single dose of dexamethasone (VetOne, Boise, Idaho, $0.03 \mathrm{mg} / \mathrm{kg}$ IV once) was administered, and hydroxyzine (Epic Pharma, Springfield Gardens, NY, $1.1 \mathrm{mg} / \mathrm{kg}$ PO, q12h) treatment was initiated. Although the mare initially improved clinically with decreased resentment to dorsoflexion of the neck under saddle, her head carriage continued to be abnormally low. Repeat hematology showed continued lymphopenia ( $1,071 \mathrm{cells} / \mu \mathrm{l}$; RI 1,500-5,500 cells $/ \mu \mathrm{l})$ and the development of mild hyperfibrinogenemia (308

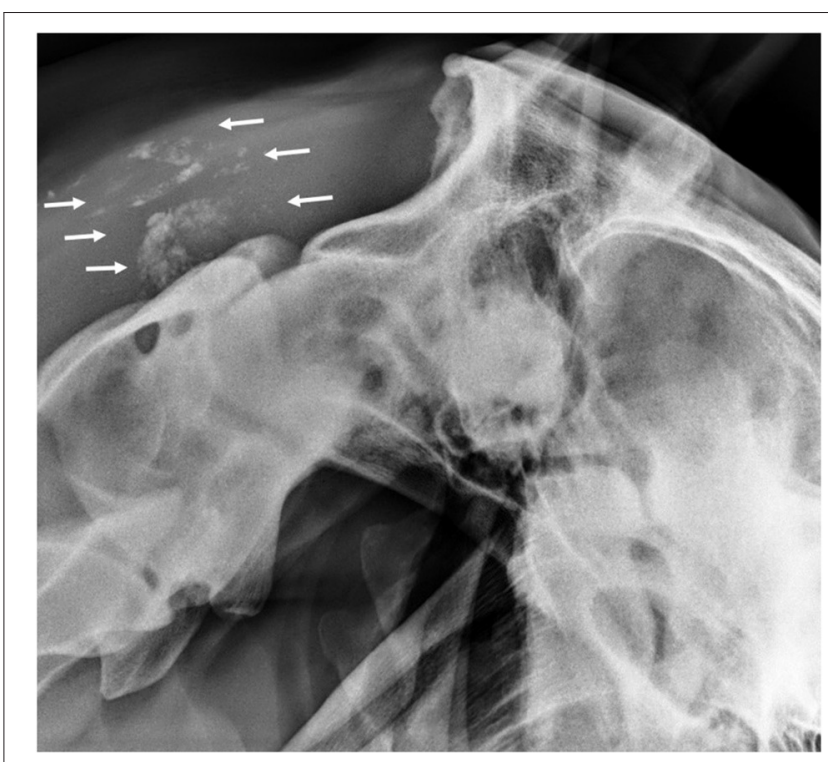

FIGURE 1 | Lateral radiograph of the atlanto-occipital joint showing mineralization in the region of the nuchal bursa (arrows).

$\mathrm{mg} / \mathrm{dl}$; RI 76-230 mg/dl). Nine days after initiating treatment, SAA was negative, but the mare's abnormally low neck posture returned and the she exhibited pain on palpation of the poll. Minocycline was continued, the hydroxyzine dose was reduced $(1 \mathrm{mg} / \mathrm{kg}, \mathrm{PO}, \mathrm{q} 12 \mathrm{~h}$ ), and phenylbutazone (Vetribute, VetOne, Boise, Idaho, $2.2 \mathrm{mg} / \mathrm{kg}$ PO q12h) was administered. Radiographs (Figure 1) and ultrasound (Figure 2) of the poll area revealed ossification and mineralization dorsal to the first $(\mathrm{C} 1)$ and second (C2) cervical vertebrae, as well as hyperechoic fluid in the cranial aspect of the nuchal bursa. Clinical signs progressed over the following week and coincided with increased SAA. The mare became reluctant to walk, her neck carriage progressively lowered, and she developed a left head tilt resulting in referral to the University of Pennsylvania, New Bolton Center (NBC) for bursoscopy and surgical debridement of the nuchal bursa.

On presentation to $\mathrm{NBC}$, the mare was bright and alert, with normal vital parameters. Mild non-painful swelling was noted over the poll area, most significantly on the right side. Baseline hematology showed moderate hyperfibrinogenemia (605 mg/dl; RI 150-375 mg/dl) and increased SAA (1,205 $\mu \mathrm{g} / \mathrm{ml}$; RI $0-24 \mu \mathrm{g} / \mathrm{ml})$. Ultrasonographic evaluation revealed synovial proliferation and marked distension of the nuchal bursa with hyperechoic fluid. The dorsal bursa region on the right side of $\mathrm{C} 1$ had evidence of fistula formation between the bursa capsule and subcutis. Cytology performed on bursal fluid revealed increased white blood cell count $(11,090 / \mu \mathrm{l} ; \mathrm{RI}<500 / \mu \mathrm{l})$ and total protein $(5.1 \mathrm{~g} / \mathrm{dl} ; \mathrm{RI}<2.0 \mathrm{~g} / \mathrm{dl})$. This sample later tested positive by PCR for B. burgdorferi. B. abortus serology, measured by card agglutination, yielded negative results.

Endoscopic evaluation of the nuchal bursa was performed under general anesthesia. Moderate synovial proliferation and turbid bursal fluid were noted, which are expected for cases 


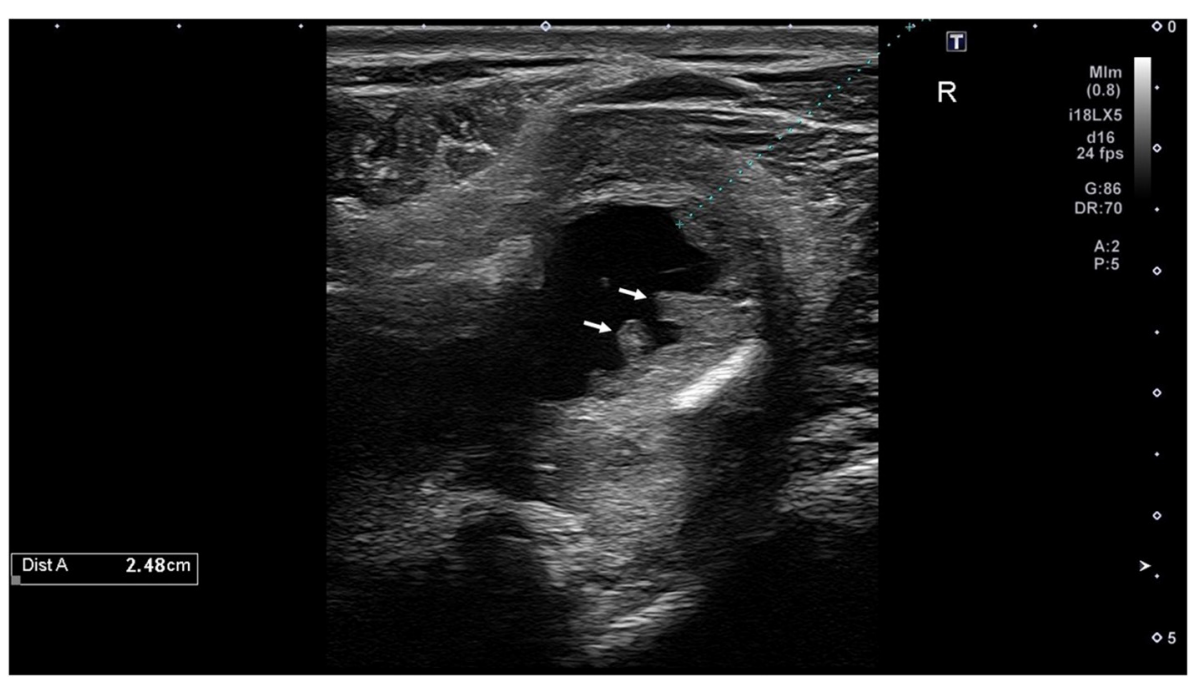

FIGURE 2 | Ultrasound image of the cranial nuchal bursa showing marked distension with anechoic fluid and synovial proliferation (arrows).

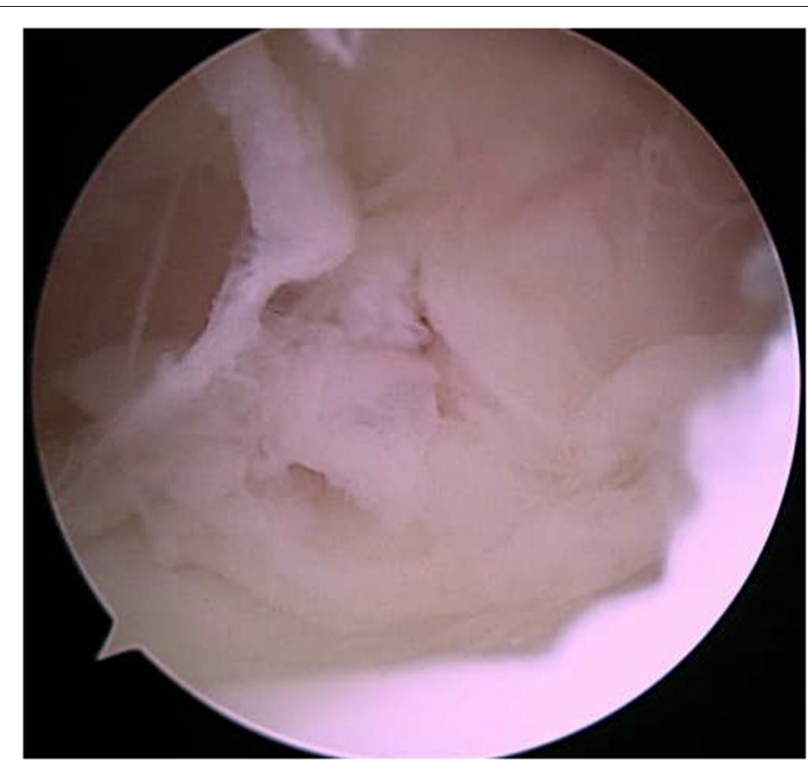

FIGURE 3 | Bursoscopy image showing synovial proliferation within the cranial nuchal bursa.

of nuchal bursitis (Figure 3). Copious lavage and synovial debridement using an endoscopic mechanical shaver was performed and the incisions closed routinely. Postoperatively, the mare was maintained on minocycline $(4 \mathrm{mg} / \mathrm{kg}$ PO $12 \mathrm{~h})$ and phenylbutazone $(2.2 \mathrm{mg} / \mathrm{kg} \mathrm{PO} \mathrm{q} 12 \mathrm{~h})$. Clinical signs improved initially; however, during the week after discharge, the mare developed fever $\left(102.3^{\circ} \mathrm{F}\right)$, facial hyperesthesia and muscle fasciculations, and abnormal vocalization with head movement. Flunixin meglumine $(0.5 \mathrm{mg} / \mathrm{kg}$ IV) was administered and hematology revealed continued elevation of SAA, moderate lymphopenia (616 cells/ $\mu \mathrm{l}$; RI 1,500-5,500 cells/ $\mu \mathrm{l}$ ), and mild hyperfibrinogenemia ( $317 \mathrm{mg} / \mathrm{dl}$; RI 76-230 mg/dl). The bursal fluid was aseptically sampled by the primary care veterinarian and appeared grossly normal. The bursa was then injected with amikacin (Amiglyde, Zoetis, Kalamazoo, MI, $1 \mathrm{~g} / 4 \mathrm{ml}$ ) and hyaluronic acid (Hyvisc, Boehringer Ingelheim, $22 \mathrm{mg} / 2 \mathrm{ml}$ ). Due to lack of clinical improvement and continued fever over the following $24 \mathrm{~h}$, the mare returned to $\mathrm{NBC}$ for further evaluation. On presentation, she was febrile $\left(101.9^{\circ} \mathrm{F}\right)$ with muscle fasciculations on the right side of her face and diffusely across the tongue. She exhibited facial hyperesthesia and resistance to lateral movement and ventroflexion of the neck. A cranial nerve examination showed no loss of function; however, dynamic neurologic gait examination revealed grade $2 / 5$ ataxia of all four limbs on the modified Mayhew scale $(15,16)$. Hematology showed lymphopenia (540 cells/ $\mu$ l; RI 1,320-5,860 cells/ $\mu \mathrm{l}$ ), hyperfibrinogenemia (907 mg/dl; RI 150-375 mg/dl), and anemia characterized by low hematocrit (24.5\%; RI 30-49\%) and low red blood cell count (5,110 cells/ $\mu$ l; RI 5,300-10,500 cells/ $\mu \mathrm{l}$ ). Cerebrospinal fluid (CSF) was collected via lumbosacral approach and cytology revealed elevated total protein (124 $\mathrm{mg} / \mathrm{dl} ; \mathrm{RI}<90 \mathrm{mg} / \mathrm{dl})$. Equine protozoal myeloencephalitis snSAG 2, 4/3 ELISA serum:CSF ratio was negative (Equine Diagnostics Solutions, Lexington, KY). Lyme multiplex assay on CSF indicated elevated antibodies directed against the infection markers OspC (1,104 MFI) and OspF (1,362 MFI), while OspA $(13,637 \mathrm{MFI})$ was decreased relative to serum levels, which measured OspA (24,992 MFI; RI <2,000), OspC (213 MFI; RI <1,000 MFI), and OspF (313 MFI; RI <1,250 MFI). B. burgdorferi PCR was negative on CSF, but a tentative diagnosis of neuroborreliosis was made based on clinical signs, abnormal CSF cytology and antibody test results, and treatment with ceftiofur sodium (Naxcel, Zoetis, Parsippany-Troy Hills, NJ, $4 \mathrm{mg} / \mathrm{kg}$ IV q12h) was initiated. Fever resolved within $24 \mathrm{~h}$ and the mare remained hospitalized for 1 week, during which time facial hyperesthesia decreased and neck stiffness 
improved. The mare was discharged with phenylbutazone (1.1 $\mathrm{mg} / \mathrm{kg}$ PO q12h), gabapentin (Neurontin, Pfizer, Gladstone, NJ, $17 \mathrm{mg} / \mathrm{kg}$ PO q12h), and vitamin E (Elevate W.S., Kentucky Performance Products, Versailles, KY, 10 IU/kg PO q24h), in addition to continued ceftiofur (switched to generic brand after 2 weeks; Ceftiflex, Med-Pharmex Inc., Pomona, CA, 4 mg/kg IV q12h). Over the following 80 days, IV ceftiofur was continued twice daily.

Approximately 8 weeks after discharge, the mare returned for examination. Fibrinogen remained mildly elevated (533 $\mathrm{mg} / \mathrm{dl}$; RI $150-375 \mathrm{mg} / \mathrm{dl})$. Palpation of the poll revealed a firm, asymmetrical swelling on the right lateral aspect with surrounding hair loss/dermatitis. An ultrasound of the nuchal bursa was performed, which revealed a moderate amount of echogenic fluid with thick surrounding capsular tissue. Approximately $25 \mathrm{ml}$ of thick, yellow/orange fluid was aseptically obtained from the cranial nuchal bursa under ultrasound guidance. Cytology performed on this fluid revealed increased white blood cell count $(75,840$ cells $/ \mu \mathrm{l} ; \mathrm{RI}<500$ cells $/ \mu \mathrm{l})$ and increased total protein $(6.1 \mathrm{~g} / \mathrm{dl} ; \mathrm{RI}<2.0 \mathrm{~g} / \mathrm{dl})$; leukocyte differential consisted of $97 \%$ poorly preserved and degenerative neutrophils, $1 \%$ small lymphocytes, and $2 \%$ macrophages amid streaming nuclear debris. The fluid was PCR positive for B. burgdorferi, contained antibodies to OspA (24,356 MFI), and no aerobic or anaerobic organisms were obtained in culture. The bursa was injected with $40 \mathrm{mg}$ methylprednisolone acetate (Depo-Medrol; Zoetis) and ceftiofur (1g). Two weeks later, another cranial nuchal bursa ultrasound revealed a subcutaneous pocket of anechoic fluid containing fibrin, with a tract to the cranial nuchal bursa. Aseptic fluid aspiration from the subcutaneous fluid pocket was unsuccessful, and the cranial nuchal bursa was injected with $40 \mathrm{mg}$ methylprednisolone acetate (Depo-Medrol; Zoetis), $2 \mathrm{ml}$ hyaluronate sodium (Hyvisc; Boehringer Ingelheim), and ceftiofur ( $1 \mathrm{~g})$.

A third and final bursa injection of ceftiofur $(1 \mathrm{~g})$ was performed 1 week after IV ceftiofur was discontinued. At that time, the mare had become febrile $\left(101.7^{\circ} \mathrm{F}\right)$ and oral minocycline was restarted ( $4 \mathrm{mg} / \mathrm{kg}$ PO q2h). One week later, a draining tract formed and opened above the nuchal bursa; the fluid was PCR positive for B. burgdorferi. After the tract drained, fibrinogen levels returned to normal. Minocycline was discontinued 3 months later. A Lyme multiplex assay performed on serum 1 month after discontinuation of minocycline revealed declining OspA antibody values (8,232 MFI; RI <2,000), which continued to decline when tested again after another 3 months $(6,255 \mathrm{MFI}$; RI <2,000). The mare returned to normal work approximately 6 months after initial presentation, with no recrudescence of clinical signs over the following year to date.

\section{DISCUSSION}

Nuchal bursitis is an important differential to consider in the horse when pain and stiffness of the head and neck is observed. Ultrasound imaging is a common modality used in the diagnosis of nuchal bursitis (17), and infectious causes should be considered and investigated.

We have described the involvement of $B$. burgdorferi in a case of equine nuchal bursitis, further supporting the significance of previous findings of $B$. burgdorferi in bursal fluid from horses diagnosed with cranial nuchal bursitis (3). In this case, in addition to identifying B. burgdorferi DNA in serial samples of bursal fluid and its associated draining tract, the serologic results provide additional support for this atypical infection. Specifically, the substantially elevated OspA antibody values found in the serum and the bursal fluid suggest the presence of $B$. burgdorferi within the bursa. The reduction in serum OspA antibody values after treatment suggests that clearance of $B$. burgdorferi organism was associated with the resolution of clinical signs.

Antibodies directed against OspA, in the absence of a history of vaccination with this antigen, are typically considered an early infection marker $(9,10)$; however, this does not encompass the clinical variations observed for these antibody values in practice. The OspA protein, which is expressed to allow adherence and colonization of $B$. burgdorferi in the tick midgut, is downregulated to allow for infection of the mammalian host (18). However, some antigen remains on the surface in the early stage of infection (19), resulting in the modest OspA antibody response observed in the early stage of infection (20). In a field setting, therefore, low positive OspA antibodies might persist as a result of regular exposure to B. burgdorferi-infected ticks. However, high OspA antibody values would not be expected in the mammalian host since OspA is not typically produced by $B$. burgdorferi in the course of infection $(19,21)$. In addition to OspA expression in the tick gut, however, it is known that $B$. burgdorferi readily expresses this protein at other times, in particular, when grown in vitro (21). The high positive OspA antibodies detected in the case reported here would have resulted from significant immune stimulation, suggesting that $B$. burgdorferi may have altered its metabolic profile to upregulate OspA expression in vivo in this equine patient. Indeed, this alteration in protein expression has been described in a mouse model, where host-adapted B. burgdorferi residing in an inflammatory in vivo environment upregulated OspA expression (22).

Only three clinical syndromes associated with equine Lyme disease caused by $B$. burgdorferi infection in the horse have been well described in the literature. Neuroborreliosis, the most well-described clinical syndrome, has been associated with the development of neurologic deficits, hyperesthesia, behavioral changes, and neck and back stiffness or pain (2329). Uveitis can manifest as ocular inflammation secondary to B. burgdorferi infection in the eye $(11,30)$, and a third clinical syndrome associated with equine Lyme disease is cutaneous pseudolymphoma, characterized by skin masses at the site of the tick bite $(31,32)$. In addition, experimental infection studies revealed that $B$. burgdorferi has a tropism for synovial membranes, and a few case reports associate $B$. burgdorferi infection with synovitis and lameness in the horse $(24,30,33,34)$.

Experimental infection studies in horses, although limited in breadth, do not reveal a high occurrence of clinical disease associated with B. burgdorferi infection (32, 35-37). 
This suggests that horses that develop clinical disease may have some additional underlying condition, such as a coinfection or immunosuppression. In humans, co-infections have been suggested to be associated with Lyme disease; however, this conjecture is not supported by the literature $(38,39)$. Immunosuppression, specifically common variable immune deficiency, has been associated with cases of neuroborreliosis in horses $(25,29)$, and immunosuppressed dogs are more susceptible to B. burgdorferi infection (40). In the case reported here, the persistent lymphopenia suggests immunosuppression, but it is possible that this hematologic change is related to an immune suppressive mechanism of B. burgdorferi (41). It is also possible in the case reported here that the immunomodulatory effects of the previously prescribed medications, such as altrenogest $(42,43)$ and quercetin (a component of Platinum Skin and Allergy) $(44,45)$, had an impact on susceptibility to infection; in particular, there is some evidence that flavonoids, such as quercetin, can induce a regulatory immune response, which has the potential to allow for the persistence of pathogen (46). Finally, the horse in this case report had been diagnosed with PPID, a common endocrine disease of older horses associated with immune suppression (47).

Well-defined equine treatment regimens for B. burgdorferi infection have not yet been established, and for this reason treatment protocols are currently based on both in vitro antibiotic susceptibility data and human protocols $(5,48)$. Successful treatment of human patients with the neurologic form of Lyme disease has been achieved with parenteral cephalosporin administration (49). Treatment with ceftiofur sodium via both intravenous and intra-bursal routes was implemented in this case due to the bacteriocidal nature of this antibiotic and documented in vitro susceptibility of $B$. burgdorferi (50). The prolonged treatment course in this case with intravenous ceftiofur sodium was based on the patient's duration to resolution of clinical signs.

It is important to note that no bacterial organisms were isolated from the bursal fluid samples in this case, and while $B$. burgdorferi is notoriously difficult to culture from the mammalian host (51), B. burgdorferi DNA was identified within the bursal fluid. Nucleic acid can persist long after an organism is no longer viable, but the continued presence of B. burgdorferi DNA in serial bursal fluid samples supports the existence of this organism at this site of infection. It is unlikely that identification

\section{REFERENCES}

1. Merillat LA. Fistula of the Withers and Poll-evil. American Veterinary Publishing Company (1917). p. 152. doi: 10.5962/bhl.title.2 5132

2. Denny HR, A. Review of brucellosis in the horse. Equine Vet J. (1973) 5:121-5. doi: 10.1111/j.2042-3306.1973.tb03208.x

3. Bergren AL, Abuja GA, Bubeck KA, Spoormakers TJP, García-López JM. Diagnosis, treatment and outcome of cranial nuchal bursitis in 30 horses. Equine Vet J. (2018) 50:465-9. doi: 10.1111/evj.12787

4. Garcia-Lòpez JM, Jenei T, Chope K, Bubeck KA. Diagnosis and management of cranial and caudal nuchal bursitis in four horses. J Am Vet Med Assoc. (2010) 237:823-9. doi: 10.2460/javma.237.7.823 of B. burgdorferi DNA was incidental in this case, as it is not common to find B. burgdorferi in joint fluid. Internal laboratory data from the Animal Health Diagnostic Center (AHDC) at Cornell University revealed that $B$. burgdorferi DNA was not detected in over $93 \%$ of all joint fluid and bursa samples submitted for B. burgdorferi PCR testing from 2007 to 2020, while it is estimated that greater than $45 \%$ of horses located in the Northeast region of the USA have serologic evidence of infection (52). The reported complaints in horses with B. burgdorferi PCRpositive joint fluid and bursa samples submitted to the AHDC included neck pain/stiffness, poll swelling, chronic draining tract at the poll, and acute onset of cranial nuchal bursitis, all of which are reported clinical signs of equine cranial nuchal bursitis, further supporting that B. burgdorferi infection can be associated with the pathogenesis of cranial nuchal bursitis in the horse.

In conclusion, Lyme disease is an insidious infection caused by $B$. burgdorferi that is notoriously difficult to diagnose and treat. Typically, antibodies directed against OspC and/or OspF are identified after infection with $B$. burgdorferi in horses, but this case suggests that substantially elevated OspA antibodies alone may be an indication of infection. In cases of suspected clinical Lyme disease, the lack of antibodies against the typical infection markers OspC and OspF may not rule out infection, and in the absence of a history of vaccination against Lyme disease, substantially elevated OspA antibodies may support a diagnosis of Lyme disease and warrant treatment. Finally, infection with B. burgdorferi should be considered as a differential in cases of equine septic nuchal bursitis.

\section{DATA AVAILABILITY STATEMENT}

The original contributions presented in the study are included in the article/supplementary material, further inquiries can be directed to the corresponding author/s.

\section{AUTHOR CONTRIBUTIONS}

CG and TP-W produced the initial manuscript draft. All authors reviewed, contributed, and approved the final version for publication. AJ oversaw patient care in hospital, JM oversaw patient care on farm, and DL performed the surgery.
5. Divers TJ, Gardner RB, Madigan JE, Witonsky SG, Bertone JJ, Swinebroad $\mathrm{EL}$, et al. Borrelia burgdorferi infection and lyme disease in north american horses: a consensus statement. J Veter Internal Med. (2018) 32:61732. doi: 10.1111/jvim.15042

6. Caine JA, Coburn J, A. short-term Borrelia burgdorferi infection model identifies tissue tropisms and bloodstream survival conferred by adhesion proteins. Infect Immun. (2015) 83:3184-94. doi: 10.1128/IAI. 00349-15

7. Wagner B, Freer H, Rollins A, Erb HN, Lu Z, Gröhn Y. Development of a multiplex assay for the detection of antibodies to Borrelia burgdorferi in horses and its validation using Bayesian and conventional statistical methods. Vet Immunol Immunopathol. (2011) 144:374-81. doi: 10.1016/j.vetimm.2011.08.005 
8. Guarino C, Asbie S, Rohde J, Glaser A, Wagner B. Vaccination of horses with Lyme vaccines for dogs induces short-lasting antibody responses. Vaccine. (2017) 35:4140-7. doi: 10.1016/j.vaccine.2017.06.052

9. Wagner B, Freer H, Rollins A, Garcia-Tapia D, Erb HN, Earnhart C, et al. Antibodies to borrelia burgdorferi OspA, OspC, OspF, and C6 antigens as markers for early and late infection in dogs. Clin Vaccine Immunol. (2012) 19:527-35. doi: 10.1128/CVI.05653-11

10. Funk RA, Pleasant RS, Witonsky SG, Reeder DS, Werre SR, Hodgson DR. Seroprevalence of borrelia burgdorferi in horses presented for coggins testing in southwest virginia and change in positive test results approximately 1 year later. J Vet Intern Med. (2016) 30:1300-4. doi: 10.1111/jvim.13973

11. Priest HL, Irby NL, Schlafer DH, Divers TJ, Wagner B, Glaser AL, et al. Diagnosis of Borrelia-associated uveitis in two horses. Vet Ophthalmol. (2012) 15:398-405. doi: 10.1111/j.1463-5224.2012.01000.x

12. Schubach WH, Mudri S, Dattwyler RJ, Luft BJ. Mapping antibody-binding domains of the major outer surface membrane protein (OspA) of Borrelia burgdorferi. Infect Immun. (1991) 59:1911-5. doi: 10.1128/iai.59.6.1911-1915.1991

13. Shanafelt M-C, Anzola J, Soderberg C, Yssel H, Turck CW, Peltz G. Epitopes on the outer surface protein A of Borrelia burgdorferi recognized by antibodies and T cells of patients with Lyme disease. Journal of Immunology. (1992) 148:218-24.

14. Akin E, McHugh GL, Flavell RA, Fikrig E, Steere AC. The immunoglobulin (IgG) antibody response to OspA and OspB correlates with severe and prolonged lyme arthritis and the iGg response to p35 correlates with mild and brief arthritis. Infect Immun. (1999) 67:173-81. doi: 10.1128/IAI.67.1.173-181.1999

15. Mayhew IG. deLahunta A, Whitlock RH, Krook L, Tasker JB. Spinal cord disease in the horse Cornell Vet. (1978) 68 Suppl 6:1-207.

16. Furr M, Reed S. Examination of the Nervous System. In: Equine Neurology. John Wiley \& Sons, Ltd (2015). p. 65-78. Available online at: http:// onlinelibrary.wiley.com/doi/abs/10.1002/9781118993712.ch6. (accessed May 14, 2021) doi: 10.1002/9781118993712.ch6

17. Abuja GA, García-López JM, Manso-Díaz G, Spoormakers TJP, Taeymans O. The cranial nuchal bursa: Anatomy, ultrasonography, magnetic resonance imaging and endoscopic approach. Equine Vet J. (2014) 46:745-50. doi: 10.1111/evj.12226

18. Yang XF, Pal U, Alani SM, Fikrig E, Norgard MV. Essential role for OspA/B in the life cycle of the Lyme disease spirochete. J Exp Med. (2004) 199:6418. doi: 10.1084/jem.20031960

19. Montgomery RR, Malawista SE, Feen KJ, Bockenstedt LK. Direct demonstration of antigenic substitution of Borrelia burgdorferi ex vivo: exploration of the paradox of the early immune response to outer surface proteins A and C in Lyme disease. J Exp Med. (1996) 183:261-9. doi: 10.1084/jem.183.1.261

20. Golde WT, Kappel KJ, Dequesne G, Feron C, Plainchamp D, Capiau C, et al. Tick transmission of Borrelia burgdorferi to inbred strains of mice induces an antibody response to P39 but not to outer surface protein A. Infect Immun. (1994) 62:2625-7. doi: 10.1128/iai.62.6.2625-2627. 1994

21. Xu Q, McShan K, Liang FT. Two regulatory elements required for enhancing ospA expression in Borrelia burgdorferi grown in vitro but repressing its expression during mammalian infection. Microbiology. 2010 156:2194-204. doi: $10.1099 /$ mic.0.036 608-0

22. Crowley H, Huber BT. Host-Adapted Borrelia burgdorferi in Mice Expresses OspA during Inflammation. Infect Immun. (2003) 71:400310. doi: 10.1128/IAI.71.7.4003-4010.2003

23. Burgess EC, Mattison M. Encephalitis associated with Borrelia burgdorferi infection in a horse. J Am Vet Med Assoc. (1987) 191:1457-8.

24. Hahn CN, Mayhew IG, Whitwell KE, Smith KC, Carey D, Carter SD, et al. A possible case of Lyme borreliosis in a horse in the UK. Equine Vet J. (1996) 28:84-8. doi: 10.1111/j.2042-3306.1996.tb01595.x

25. James FM, Engiles JB, Beech J. Meningitis, cranial neuritis, and radiculoneuritis associated with Borrelia burgdorferi infection in a horse. J Am Vet Med Assoc. (2010) 237:1180-5. doi: 10.2460/javma.237. 10.1180
26. Imai DM, Barr BC, Daft B, Bertone JJ, Feng S, Hodzic E, et al. Lyme Neuroborreliosis in 2 Horses. Vet Pathol. (2011) 48:1151-7. doi: 10.1177/0300985811398246

27. Wagner B, Bartol J, Mahar O, Divers T. A new sensitive lyme multiplex assay to confirm neuroborreliosis in horses: a case report. In: Proceeding of the AAEP's 57th Annual Convention. San Antonio, Texas (2011). p. 70-5.

28. Johnstone L k., Engiles J b., Aceto H, Buechner-Maxwell V, Divers T, Gardner $\mathrm{R}$, et al. Retrospective evaluation of horses diagnosed with neuroborreliosis on postmortem examination: 16 Cases (2004-2015). J Vet Intern Med. (2016) 30:1305-12. doi: 10.1111/jvim.14369

29. Pecoraro HL, Felippe MJB, Miller AD, Divers TJ, Simpson KW, Guyer KM, et al. Neuroborreliosis in a horse with common variable immunodeficiency. $J$ VET Diagn Invest. (2019) 31:241-5. doi: 10.1177/1040638718824146

30. Burgess EC, Gillette D, Pickett JP. Arthritis and panuveitis as manifestations of Borrelia burgdorferi infection in a Wisconsin pony. J Am Vet Med Assoc. (1986) 189:1340-2.

31. Sears KP, Divers TJ, Neff RT, Miller Jr WH, McDonough SP, A. case of Borrelia-associated cutaneous pseudolymphoma in a horse. Vet Dermatol. (2012) 23:153-6. doi: 10.1111/j.1365-3164.2011.01013.x

32. Chang Y-F, Novosol V, McDonough SP, Chang C-F, Jacobson RH, Divers T, et al. Experimental infection of ponies with borrelia burgdorferi by exposure to ixodid ticks. Vet Pathol. (2000) 37:68-76. doi: 10.1354/vp.37-1-68

33. Magnarelli LA, Anderson JF, Shaw E, Post JE, Palka FC. Borreliosis in equids in northeastern United States. Am J Vet Res. (1988) 49:359-62.

34. Passamonti F, Veronesi F, Cappelli K, Capomaccio S, Reginato A, Miglio A, et al. Polysynovitis in a horse due to Borrelia burgdorferi sensu lato infection-case study. Ann Agric Environ Med. (2015) 22:24750. doi: 10.5604/12321966.1152074

35. Chang Y-F, Novosol V, McDonough SP, Chang C-F, Jacobson RH, Divers $\mathrm{T}$, et al. Vaccination against Lyme Disease with recombinant Borrelia burgdorferi outer-surface protein A (rOspA) in horses. Vaccine. (1999) 18:540-8. doi: 10.1016/S0264-410X(99)00187-5

36. Chang Y-F, Ku Y-W, Chang C-F, Chang C-D, McDonough SP, Divers T, et al. Antibiotic treatment of experimentally Borrelia burgdorferi-infected ponies. Vet Microbiol. (2005) 107:285-94. doi: 10.1016/j.vetmic.2005.02.006

37. Basile RC, Rivera GG, Del Rio LA, de Bonis TCM, do Amaral GPD, Giangrecco E, et al. Anaphylactoid reaction caused by sodium ceftriaxone in two horses experimentally infected by Borrelia burgdorferi. BMC Veter Res. (2015) 11:197. doi: 10.1186/s12917-015-0478-6

38. Lantos PM, Wormser GP. Chronic coinfections in patients diagnosed with chronic lyme disease: a systematic review. Am J Med. (2014) 127:110510. doi: 10.1016/j.amjmed.2014.05.036

39. Wormser GP, McKenna D, Scavarda C, Cooper D, El Khoury MY, Nowakowski J, et al. Co-infections in Persons with Early Lyme Disease, New York, USA. Emerg Infect Dis. (2019) 25:748-52. doi: 10.3201/eid2504.181509

40. Chang Y-F, Novosel V, Chang C-F, Summers BA, Ma D-P, Chiang Y-W, et al. Experimental induction of chronic borreliosis in adult dogs exposed to Borrelia burgdorferi-infected ticks and treated with dexamethasone. Am J Vet Res. (2001) 62:1104-12. doi: 10.2460/ajvr.2001.62.1104

41. Chiao JW, Pavia C, Riley M, Altmann-Lasekan W, Abolhassani M, Liegner $\mathrm{K}$, et al. Antigens of Lyme disease of spirochaete Borrelia burgdorferi inhibits antigen or mitogen-induced lymphocyte proliferation. FEMS Immunol Med Microbiol. (1994) 8:151-5. doi: 10.1111/j.1574-695X.1994.tb00437.x

42. Fedorka CE, Ball BA, Walker OF, Conley AJ, Corbin CJ, Lu KG, et al. Alteration of the mare's immune system by the synthetic progestin, altrenogest. Am J Reprodu Immunol. (2019) 82:e13145. doi: 10.1111/aji.13145

43. Neuhauser S, Palm F, Ambuehl F, Möstl E, Schwendenwein I, Aurich C. Effect of altrenogest-treatment of mares in late gestation on adrenocortical function, blood count and plasma electrolytes in their foals. Equine Vet J. (2009) 41:572-7. doi: 10.2746/042516409X394481

44. Hosseinzade A, Sadeghi O, Naghdipour Biregani A, Soukhtehzari S, Brandt GS, Esmaillzadeh A. Immunomodulatory effects of flavonoids: possible induction of $\mathrm{T}$ CD4+ regulatory cells through suppression of mTOR pathway signaling activity. Front Immunol. (2019) 10:51. doi: 10.3389/fimmu.2019.00051

45. Michalski J, Deinzer A, Stich L, Zinser E, Steinkasserer A, Knippertz I. Quercetin induces an immunoregulatory phenotype 
in maturing human dendritic cells. Immunobiology. 225:151929. doi: 10.1016/j.imbio.2020.151929

46. Sanchez AM, Yang Y. The role of natural regulatory $\mathrm{T}$ cells in infection. Immunol Res. (2011) 49:124-34. doi: 10.1007/s12026-010-8176-8

47. Miller AB, Loynachan AT, Bush HM, Hart KA, Barker VD, Campana-Emard AG, et al. Effects of pituitary pars intermedia dysfunction and Prascend (pergolide tablets) treatment on endocrine and immune function in horses. Domest Anim Endocrinol. (2021) 74:106531. doi: 10.1016/j.domaniend.2020.106531

48. Kullberg BJ, Vrijmoeth HD, van de Schoor F, Hovius JW. Lyme borreliosis: diagnosis and management. BMJ. (2020) 369:m1041. doi: 10.1136/bmj.m1041

49. Dersch R, Freitag MH, Schmidt S, Sommer H, Rauer S, Meerpohl JJ. Efficacy and safety of pharmacological treatments for acute Lyme neuroborreliosis - a systematic review. Eur J Neurol. (2015) 22:1249-59. doi: 10.1111/ene.12744

50. Caol S, Divers T, Crisman M, Chang Y-F. In vitro susceptibility of Borrelia burgdorferi isolates to three antibiotics commonly used for treating equine Lyme disease. BMC Vet Res. (2017) 13:1-16. doi: 10.1186/s12917-017-1 212-3

51. Jaulhac B, Nicolini P, Piemont Y, Monteil H. Detection of borrelia burgdorferiin cerebrospinal fluid of patients with lyme borreliosis. New England J Med. (1991) 324:98-102. doi: 10.1056/NEJM199105163 242014
52. Magnarelli LA, Ijdo JW, Van Andel AE, Wu C, Padula SJ, Fikrig E. Serologic confirmation of Ehrlichia equi and Borrelia burgdorferi infections in horses from the northeastern United States. J Am Vet Med Assoc. (2000) 217:104550. doi: 10.2460/javma.2000.217.1045

Conflict of Interest: The authors declare that the research was conducted in the absence of any commercial or financial relationships that could be construed as a potential conflict of interest.

Publisher's Note: All claims expressed in this article are solely those of the authors and do not necessarily represent those of their affiliated organizations, or those of the publisher, the editors and the reviewers. Any product that may be evaluated in this article, or claim that may be made by its manufacturer, is not guaranteed or endorsed by the publisher.

Copyright (C) 2021 Guarino, Pinn-Woodcock, Levine, Miller and Johnson. This is an open-access article distributed under the terms of the Creative Commons Attribution License (CC BY). The use, distribution or reproduction in other forums is permitted, provided the original author(s) and the copyright owner(s) are credited and that the original publication in this journal is cited, in accordance with accepted academic practice. No use, distribution or reproduction is permitted which does not comply with these terms. 